Supplemental Information for

\title{
Cooperative Conformational Change of a Single Organic Molecule for Ultrafast Rechargeable Batteries
}

Giyeong Son ${ }^{1+}$, Vitalii $\mathrm{Ri}^{2 \dagger}$, Chanwoo $\mathrm{Noh}^{3}$, Hongkwan Yoon ${ }^{2}$, Sunghyun $\mathrm{Ko}^{1}$, Joonhee Moon ${ }^{4}$, YounJoon Jung $^{3}$, Chan Beum Park ${ }^{1 *}$, and Chunjoong Kim ${ }^{2 *}$

${ }^{1}$ Department of Materials Science and Engineering, Korea Advanced Institute of Science and Technology (KAIST), 335 Science Road, Daejeon 34141, Republic of Korea

${ }^{2}$ Department of Materials Science and Engineering, Chungnam National University, 99 Daehak Road, Daejeon, 34134, Republic of Korea

${ }^{3}$ Department of Chemistry, Seoul National University, 1 Gwanak Road, Seoul, 08826, Republic of Korea

${ }^{4}$ Division of Materials Analysis, Korea Basic Science Institute (KBSI), 169-148 Gwahak Road, Daejeon, 34133, Republic of Korea

${ }^{\dagger}$ These authors contributed equally to this work.

"E-mail: parkcb@kaist.ac.kr, ckim0218@cnu.ac.kr 


\section{EXPERIMENTAL PROCEDURES}

Electrode preparation. 7-Hydroxy-3H-phenoxazin-3-one (95\%) (Sigma Aldrich, USA) was purchased and utilized in electrodes without further purification. Phenoxazin-3-one electrodes were fabricated by mixing the active material, conductive carbon (Ketjen black, EC-600JD, LION Specialty Chemicals Co., LTD.), binder (PTFE (poly(tetrafluoroethylene)) beads, Sigma Aldrich, Japan) with weight ratio of $40: 40: 20$. Solid mixing process was carried out by two steps in order to prepare uniform distribution of the components. All components were mixed in the paste mixing machine (Inter-Mixer IMX150, KM Tech, Korea), and followed by hand-mixing with mortar and pestle until the mixture dough was formed. In order to prepare the electrodes with a thickness of $\sim 150 \mathrm{um}$, the mixture dough was flattened. Electrodes were punched into $8 \mathrm{~mm}$ disks, thereby the average loading of active material in the electrode was $\sim 5 \mathrm{mg} \mathrm{cm}^{-2}$.

Electrochemistry. Coin-type cells (CR2016) were fabricated in argon-filled glovebox $\left(\mathrm{O}_{2}, \mathrm{H}_{2} \mathrm{O}: 0\right.$ ppm). Half-cells were assembled with a lithium foil as the counter and reference electrode (anode) and the phenoxazin-3-one electrode as the working electrode (cathode). Celgard 2400 was used as separator. Cells were filled with commercial carbonate electrolyte, $1 \mathrm{M} \mathrm{LiPF}_{6}$ in EC/EMC/DMC $(1: 1: 1 \mathrm{v} / \mathrm{v})$, purchased from PANAX ETEC, Korea. Electrochemical properties of phenoxazin-3-one were investigated by galvanostatic cyclings with discharge and charge cut-off voltages of $1.5 \mathrm{~V}$ and $4.0 \mathrm{~V}$, respectively, using the battery testing system (WBSC3000L, WonATech, Korea). The cycle retention was studied for fifty cycles at the current rate of $200 \mathrm{mAg}^{-1}$. Rate capability performance was also investigated under the various (dis)charging rate from $50 \mathrm{mAg}^{-1}$ to $20 \mathrm{Ag}^{-1}$ ). GITT experiment was conducted in voltage range of $1.5 \mathrm{~V}-$ 4.0 V with 5 minute current pulses of $200 \mathrm{mAg}^{-1}$ and 15 minutes relaxation time. The molar volume $\left(\mathrm{V}_{\mathrm{m}}\right)$ of the electrode was estimated to be $505.22 \mathrm{~cm}^{3} \mathrm{~mol}^{-1}$. EIS tests were performed at the pristine, first charged, and tenth charged states in the frequency range of $10^{6}-10^{-2} \mathrm{~Hz}$ using Electrochemical Workstation ZIVE BP2 (WonATech, Korea). Cyclic voltammograms of the phenoxazin-3-one electrode were obtained in voltage window of $1.5 \mathrm{~V}-4.0 \mathrm{~V}$ at various scan rates $(0.1,0.2,0.4,0.6,0.8,1.0,1.25$, and $1.5 \mathrm{mV} / \mathrm{s})$. 
Material characterization. The morphologies of electrodes were observed using an S-4800 field emission scanning electron microscopy (Hitachi Co., Japan) at an electron acceleration voltage of $3.0 \mathrm{kV}$. The surface area was measured with a surface properties analyzer instrument from Micromeritics 3Flex (Micromeritics Instrument Corp., Norcross, GA, USA). The Surface area measurements are typically based on $\mathrm{N}_{2}$ absorption at $77 \mathrm{~K}$. The Brunauer-Emmer-Teller (BET) theory is typically used to interpret the data.

Ex-situ characterization of the electrodes. For the post-mortem analysis, the electrodes were carefully harvested from the coin cells with various states of (dis)charge. All cells were carefully disassembled and rinsed thoroughly with DMC (DAEJUNG CHEMICALS, Korea) in the Ar filled glove box to prevent air exposure. X-ray photoelectron spectroscopy (XPS) measurements were conducted with X-ray photoelectron spectrometer (K-aplha ${ }^{+}$, Thermo Fisher Scientific, USA). Binding energies were calibrated to the $\mathrm{C}=\mathrm{C}$ bond of the $\mathrm{C} 1 \mathrm{~s}$ region at $284.5 \mathrm{eV}$. Fourier transform infrared spectroscopy (FTIR) spectra were recorded by a Nicolet IS50 FTIR spectrometer (Thermo Fisher Scientific., USA). The electrodes were deposited on a diamond surface. The X-ray diffraction (XRD) measurements were examined using a SmartLab (Rigaku Co., Japan) with a scan rate of $8^{\circ} \mathrm{min}^{-1}$, a range of $5-30^{\circ}$, and a $\mathrm{Cu}$ Ka1 radiation wavelength of $1.5406 \AA$.

Computational details. We conducted ab initio calculations based on density functional theory (DFT) using GAMESS program. ${ }^{1}$ Wave functions were approximated with $6-311 \mathrm{G}^{* *}(\mathrm{~d}, \mathrm{p})$ basis set, and the exchange-correlation functional was described by Becke-Lee-Yang-Parr (B3LYP) hybrid functional., Polarizable continuum model (PCM) method with dielectric constant $(\varepsilon)$ of 7.9 was implemented to implicitly consider the solvation effect. ${ }^{4}$ The atomic partial charge was calculated via atomic dipole moment corrected Hirshfeld (ADCH) method using Multiwfn program. ${ }^{5,6}$ Molecular structures and orbitals were visualized with MacMolPlt program.

Operando Raman analysis. The Operando Raman cell was designed in-house. The external housing of operando Raman cell is composed of two SUS 304 stainless steel bodies, which are separated by polyether ether ketone disk and O-rings. Each stainless steel body can work as a current collector. The 
conventional CR2032 type coin type cell with holes in all its parts except the phenoxazin-3-one electrode could be directly installed into the operando Raman cell. Quartz window mounted in the top current collector permitted the laser beam to reach the the phenoxazin-3-one electrode. The operando Raman cell was assembled in an Ar-filled glove box $\left(\mathrm{H}_{2} \mathrm{O}, \mathrm{O}_{2}<0.1 \mathrm{ppm}\right)$. A confocal Raman spectroscope (Ramanforce, Nanophoton) and objective lens Nikon x50 (NA=0.8) were used to conduct operando Raman measurement. Raman spectra were obtained during (dis)charging of the phenoxazin-3-one electrode using a $532 \mathrm{~nm}$ green laser beam. The operando Raman cell was galvanostatically cycled at $200 \mathrm{mAg}^{-1}$. 


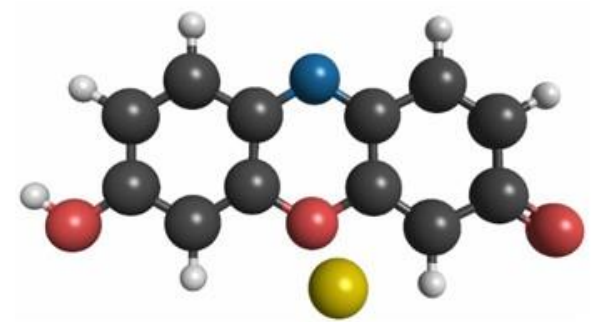

$\Delta E=0.960 \mathrm{eV}$

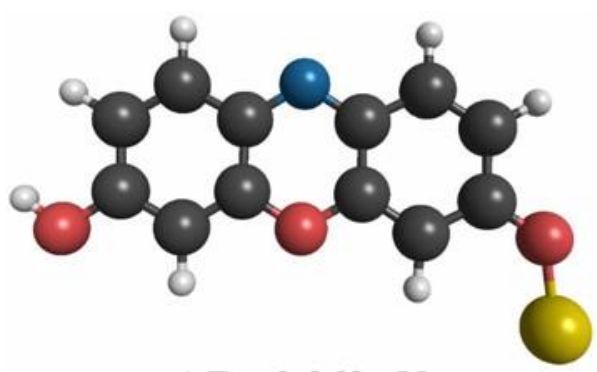

$\Delta E=0.063 \mathrm{eV}$

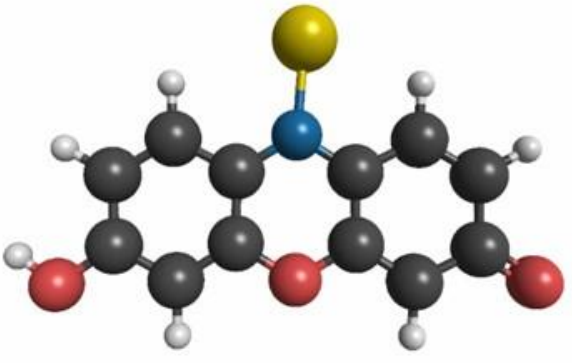

$\Delta E=0.424 \mathrm{eV}$

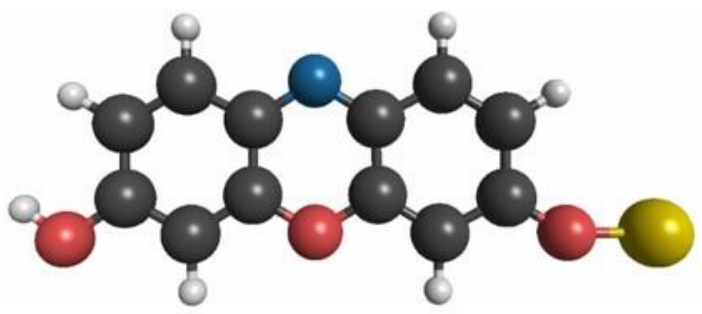

most stable

Figure S1. DFT energies calculated for phenoxazin-3-one with different lithium ion sites during lithium insertion. The carbonyl group of phenoxazin-3-one is energetically most stable binding site compared to other sites during the first reduction by lithiation. 
a

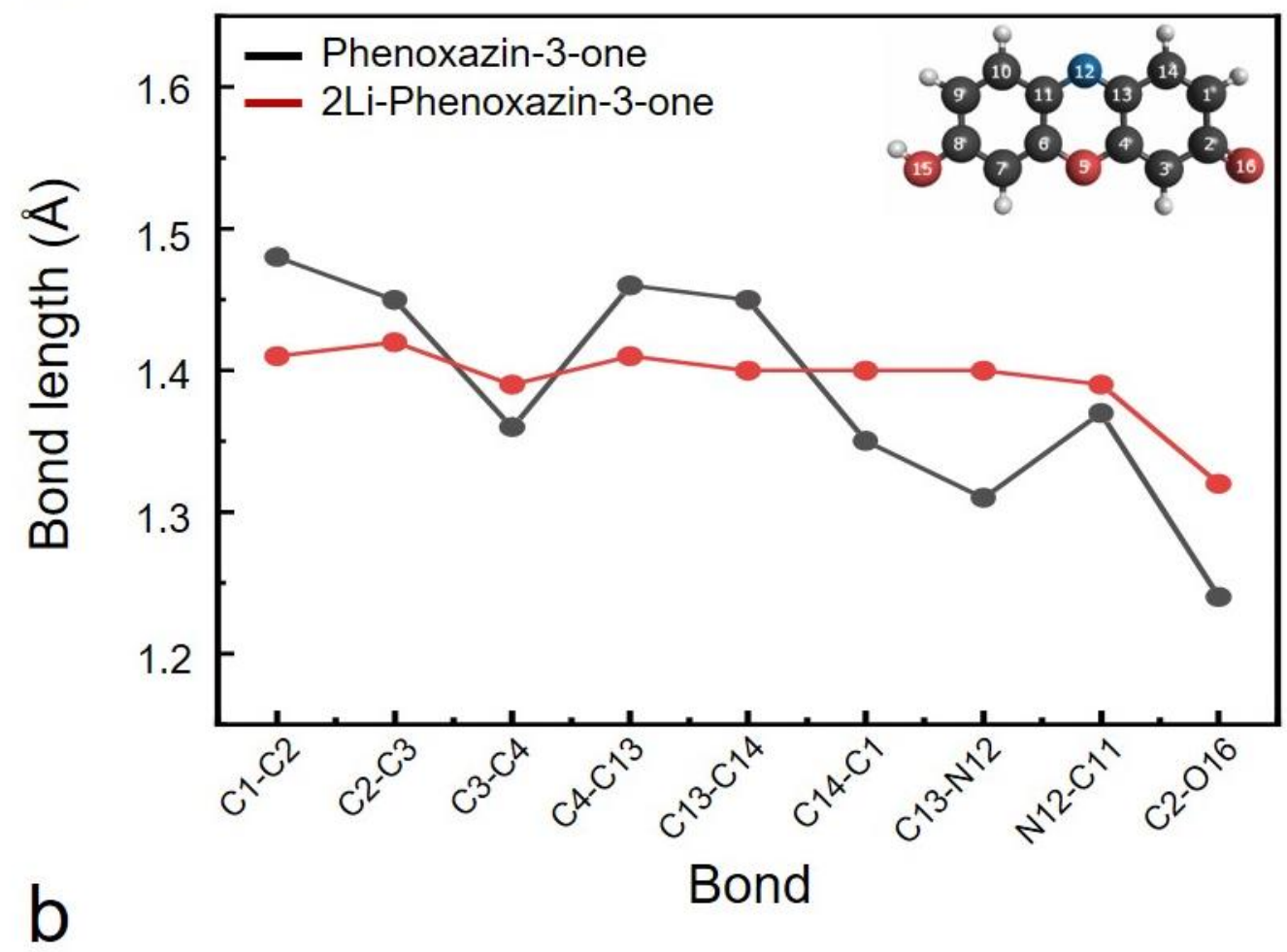

\begin{tabular}{c|ccccccccc}
\hline & C1-C2 & C2-C3 & C3-C4 & C4-C13 & C13-C14 & C14-C1 & C13-N12 N12-C11 & C2-O16 \\
\hline $\begin{array}{c}\text { Phenoxazin-3- } \\
\text { one (a) }\end{array}$ & 1.48 & 1.45 & 1.36 & 1.46 & 1.45 & 1.35 & 1.31 & 1.37 & 1.24 \\
$\begin{array}{c}\text { 2Li-Phenoxazin- } \\
\text { 3-one (b) }\end{array}$ & 1.41 & 1.42 & 1.39 & 1.41 & 1.40 & 1.40 & 1.40 & 1.39 & 1.32 \\
\hline (a)-(b) & -0.06 & -0.04 & 0.03 & -0.05 & -0.04 & 0.05 & 0.10 & 0.02 & 0.08 \\
\hline
\end{tabular}

Figure S2. (a) The bond lengths of C1-C2, C2-C3, C3-C4, C4-C13, C13-C14, C14-C1, C13-N12, N12$\mathrm{C} 11$, and $\mathrm{C} 2-\mathrm{O} 16$ of phenoxazin-3-one and 2Li-phenoxazin-3-one. (b) Comparison of the major bond lengths in the phenoxazin-3-one during discharge. Significantly increased bond lengths C13-N12 and C2O16 are highlighted in red. 
a

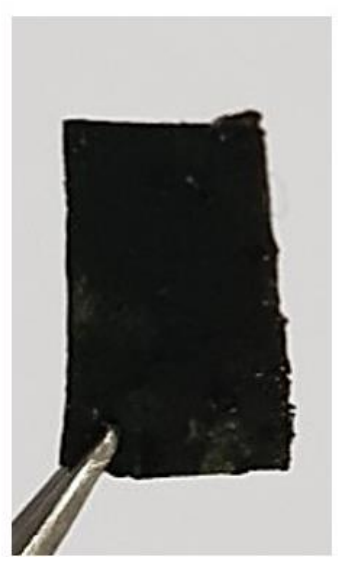

b

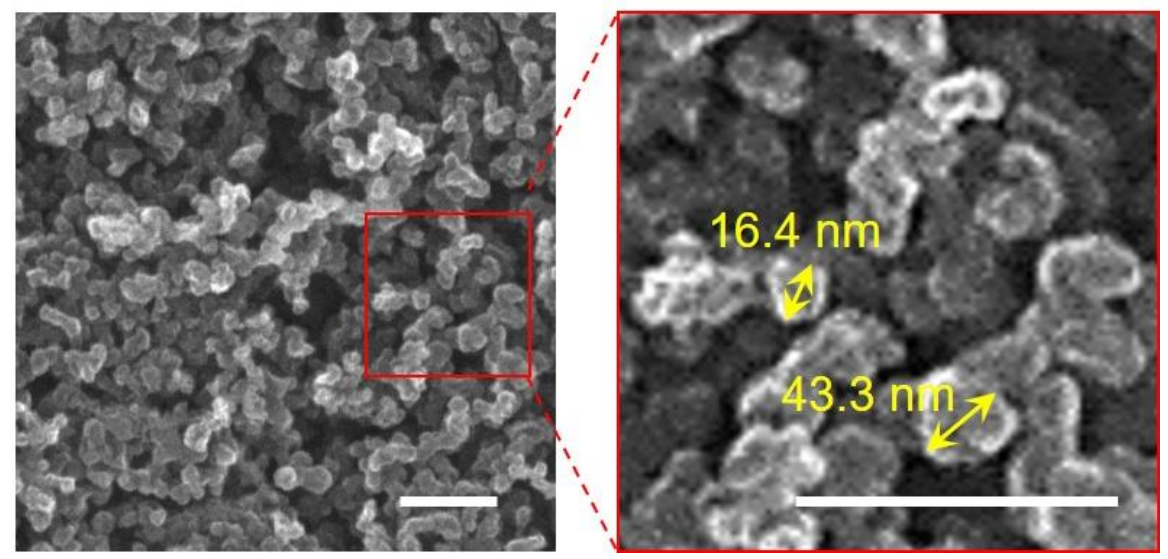

Figure S3. (a) Photograph of phenoxazin-3-one self-standing electrode. (b) SEM image of phenoxazin-3one self-standing electrode. The morphology showed $\sim 25 \mathrm{~nm}$-sized carbon dominantly in the electrode. Scale bars: $200 \mathrm{~nm}$

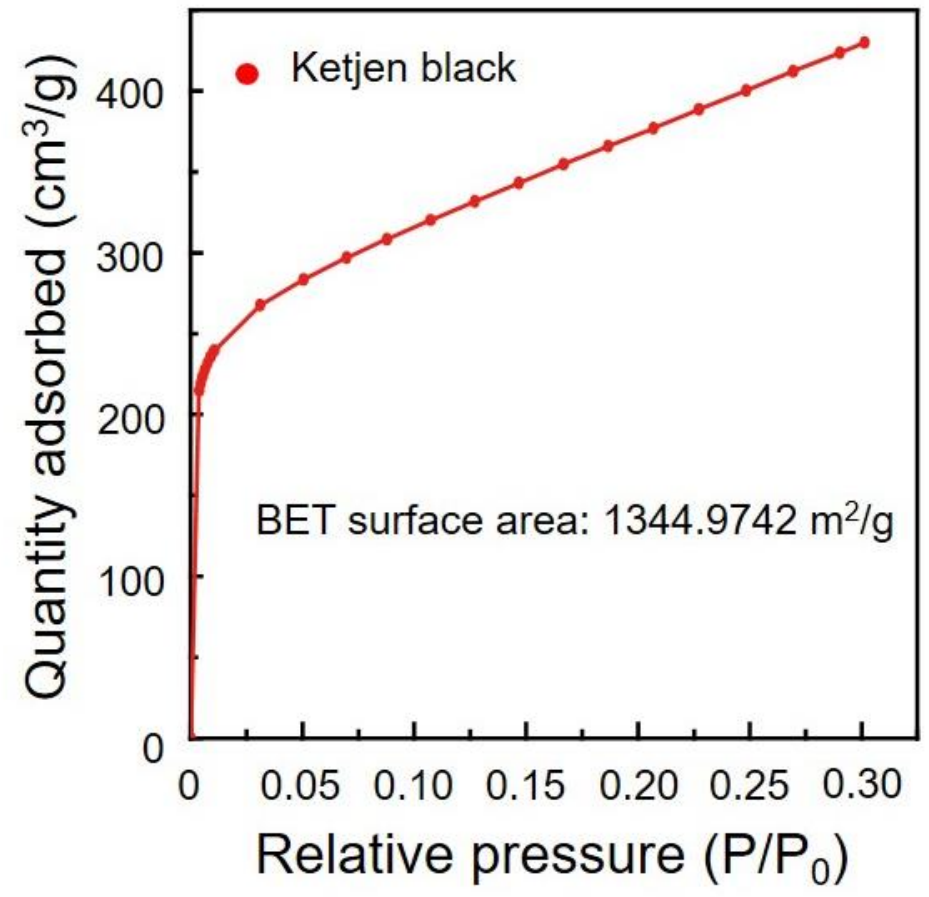

Figure S4. Surface area of Ketjen black. The Brunauer-Emmett-Teller (BET) theory is typically used to interpret the data. Analysis adsorptive: $\mathrm{N}_{2}$. Analysis bath temperature: $77 \mathrm{~K}$. 


\section{Note S1.}

Formation of the more electrochemical favorable electrode structure was confirmed by electrochemical impedance spectroscopy (EIS). EIS tests were carried out for the pristine cell and $1^{\text {st }}$ and $10^{\text {th }}$ cycled cells. The Nyquist plots are shown in Figure S5. The inset of Figure S5 depicts the equivalent circuit used to fit the impedance curves and evaluate magnitudes of various resistance components. We denote $R_{1}$ as electrolyte resistance $\left(R_{s}\right), R_{2}$ - as the solid electrolyte interface ( $\left.S E I\right)$ resistance $\left(R_{S E I}\right), R_{3}-$ as charge transfer resistance $\left(\mathrm{R}_{\mathrm{ct}}\right)$, and $\mathrm{W}_{\mathrm{o}}$ - as Warburg impedance related to the Li-ion diffusion. We estimated $\mathrm{R}_{\mathrm{s}}$, $\mathrm{R}_{\mathrm{SEI}}$ and $\mathrm{R}_{\mathrm{ct}}$ for each cell by the best fitting (green lines). $\mathrm{R}_{\mathrm{s}}, \mathrm{R}_{\mathrm{SEI}}$ and $\mathrm{R}_{\mathrm{ct}}$ of the pristine cell are estimated to be $2 \mathrm{Ohm}, 13.73 \mathrm{Ohm}$ and $234 \mathrm{Ohm}$, respectively. While $\mathrm{R}_{\mathrm{s}}$ and $\mathrm{R}_{\mathrm{SEI}}$ did not change after electrochemical cyclings, $\mathbf{R}_{\mathrm{ct}}$ decreased significantly as tabulated in the table. The drop of $\mathbf{R}_{\mathrm{ct}}$ indicates formation of more reversible and efficient electrode structure by electrochemical cycles, ultimately leading to the higher capacity and faster response.

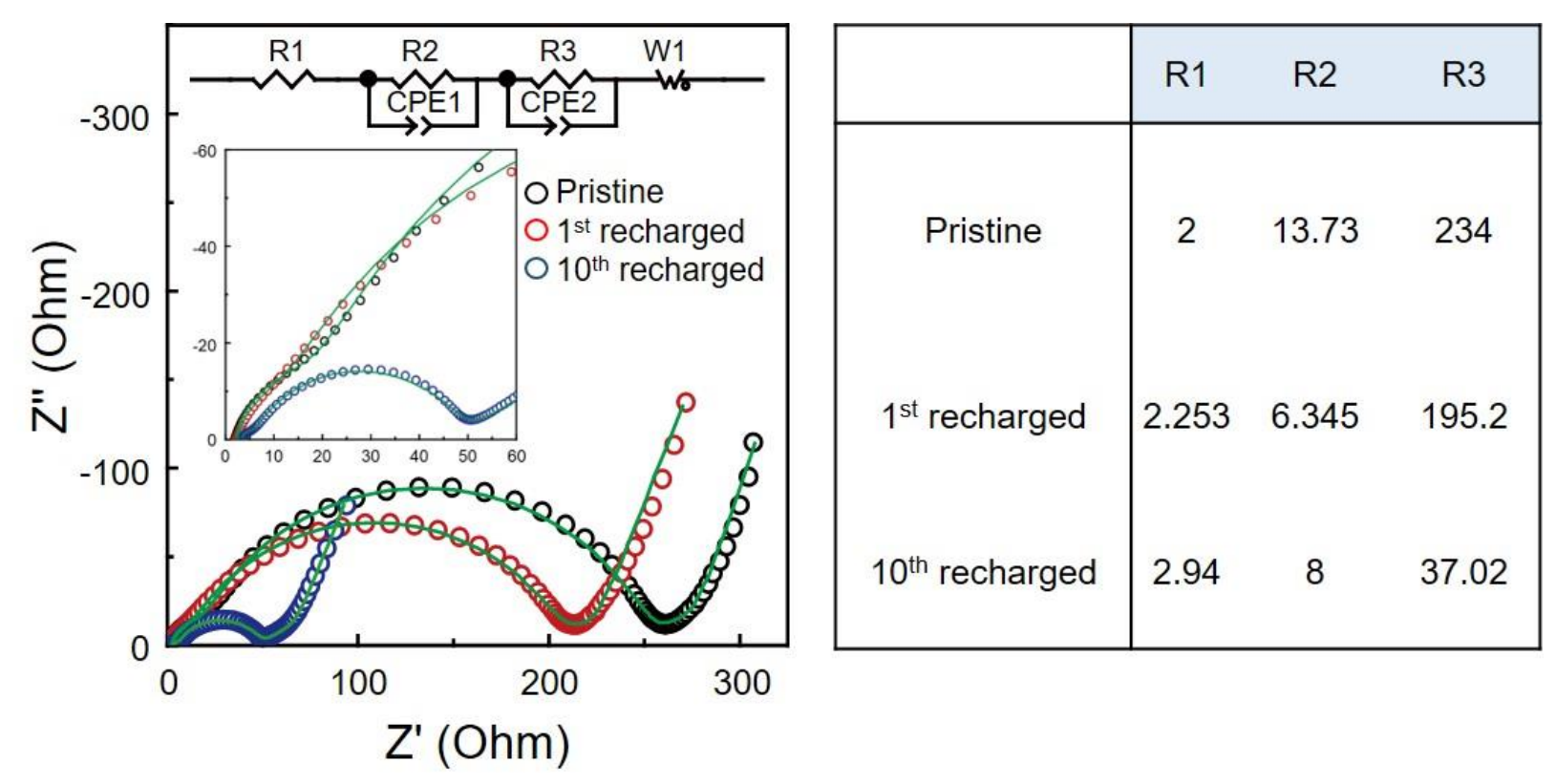

Figure S5. Electrochemical impedance spectroscopy (EIS) curves obtained at as-prepared state, after 1st cycle, and after 10th cycle. The inset displays the high-frequency region. In the equivalent circuit, R1, R2, $\mathrm{R} 3$, and W represented electrolyte resistance, SEI layer resistance, charge transfer resistance, Warburg impedance related to the $\mathrm{Li}^{+}$diffusion. 


\section{Note S2.}

Significant excess of obtained discharge capacity over the theoretical (298 mAhg ${ }^{-1}$ vs. $\left.251.5 \mathrm{mAhg}^{-1}\right)$ was partly attributed to the capacity contribution from the conductive additive. In order to estimate the carbon contribution, we prepared the electrode, in which phenoxazin-3-one was replaced by Super P carbon. Super $\mathrm{P}$ carbon showed negligible capacity above $1 \mathrm{~V}$. The galvanostatic cycling test was carried out at $200 \mathrm{mAg}^{-}$ ${ }^{1}$ in the voltage window between $1.5 \mathrm{~V}$ and $4.0 \mathrm{~V}$. voltage range. The capacity vs. voltage curves of the Ketjen black electrode are depicted in Figure S6. The Ketjen black electrode showed discharge capacity of $60 \mathrm{mAhg}^{-1}$ in the same electrochemical testing condition. Considering this, discharge capacity of the phenoxazin-3-one electrode can be estimated as $238 \mathrm{mAhg}^{-1}$, revealing $94.6 \%$ of the theoretical capacity.

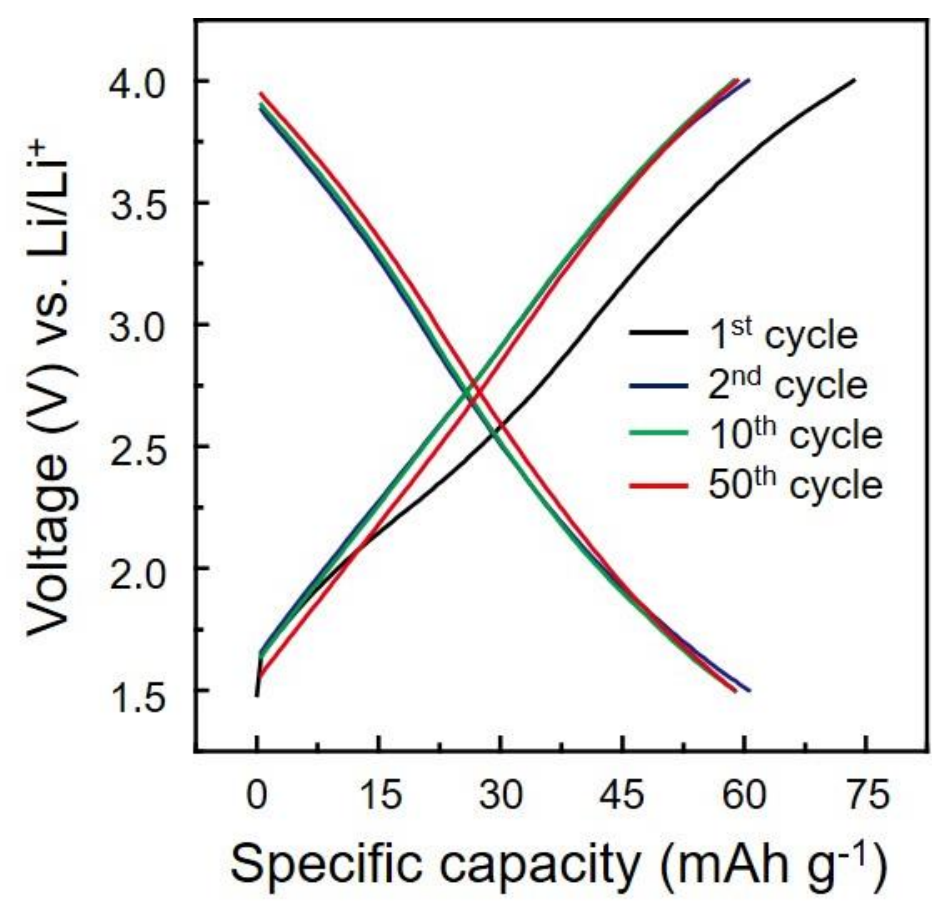

Figure S6. Voltage profile of the Ketjen black electrode, showing around $60 \mathrm{mAhg}^{-1}$ discharge capacity in the voltage range of $1.5-4 \mathrm{~V}$ 


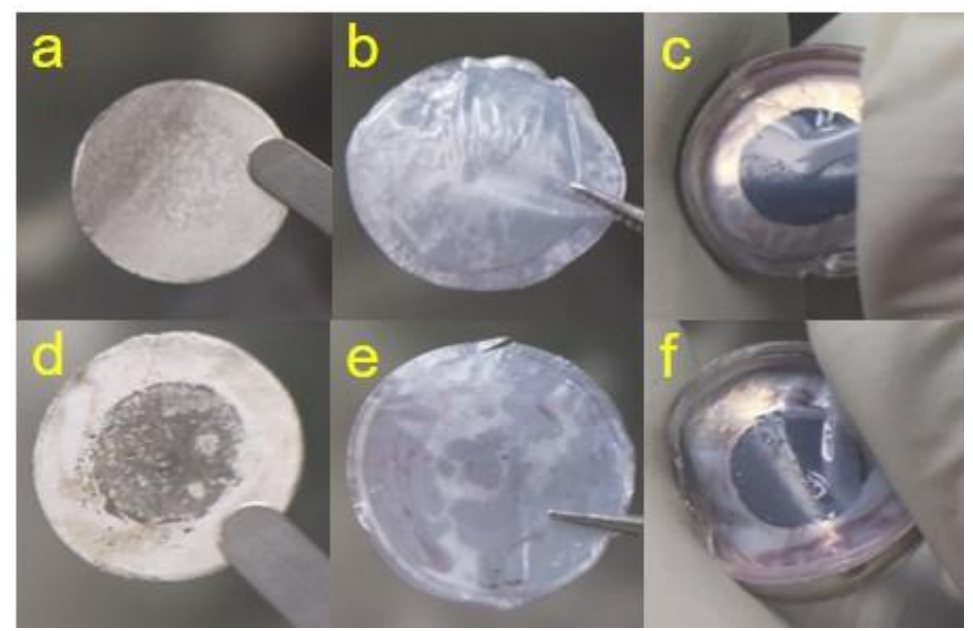

Figure S7. Photographs of (a) lithium, (b) separator and (c) phenoxazin-3-one electrode from the disassemble cell with $1 \mathrm{M} \mathrm{LiPF}_{6}$ in $\mathrm{EC} / \mathrm{DMC} / \mathrm{EMC}$, respectively after the first cycle and (d-f) those after 10 cycles.

\section{Note S3.}

The GITT experiment was conducted after 10 cycles of galvanostatic (dis)charging in order to analyze diffusion coefficient in the fully activated electrode structure. The diffusion coefficient was calculated for from equation (1)

$$
D=\frac{4}{\pi \tau}\left(\frac{n_{m} V_{m}}{S}\right)^{2}\left(\frac{\Delta E_{s}}{\Delta E_{t}}\right)^{2}
$$

where $\tau$ is the duration of the current pulse (s); $n_{m}$ is the number of moles of phenoxazin-3-one in the electrode; $\mathrm{V}_{\mathrm{m}}$ is the molar volume of the electrode derived from geometric surface area and thickness of the electrode $\left(\mathrm{cm}^{3} \mathrm{~mol}^{-1}\right) ; \mathrm{S}$ is the the contact area between electrode and electrolyte, consistent with the geometric area of the electrode $\left(\mathrm{cm}^{2}\right) ; \Delta \mathrm{E}_{\mathrm{s}}$ is the steady-state voltage change $(\mathrm{V}), \Delta \mathrm{E}_{\mathrm{t}}$ is the voltage change during the constant current pulse excluding the $i R$ drop $(\mathrm{V}) .^{7,8}$ 


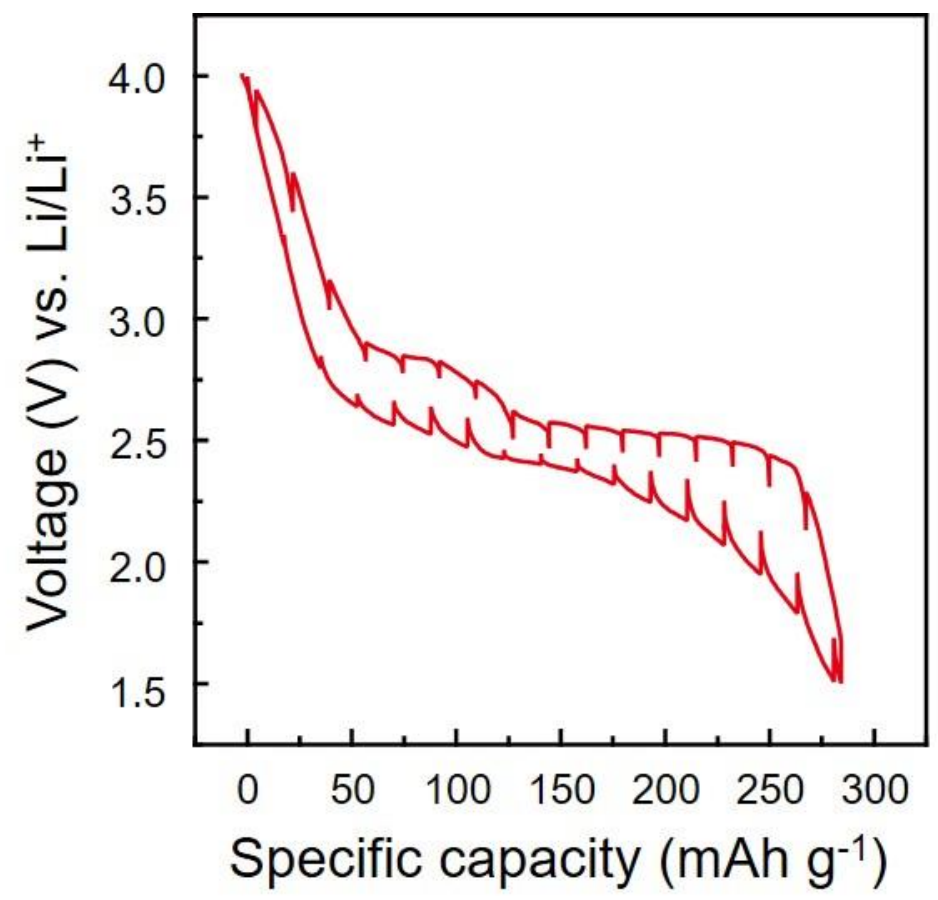

Figure S8. The galvanostatic intermittent titration technique (GITT) curve of phenoxazin-3-one electrode.

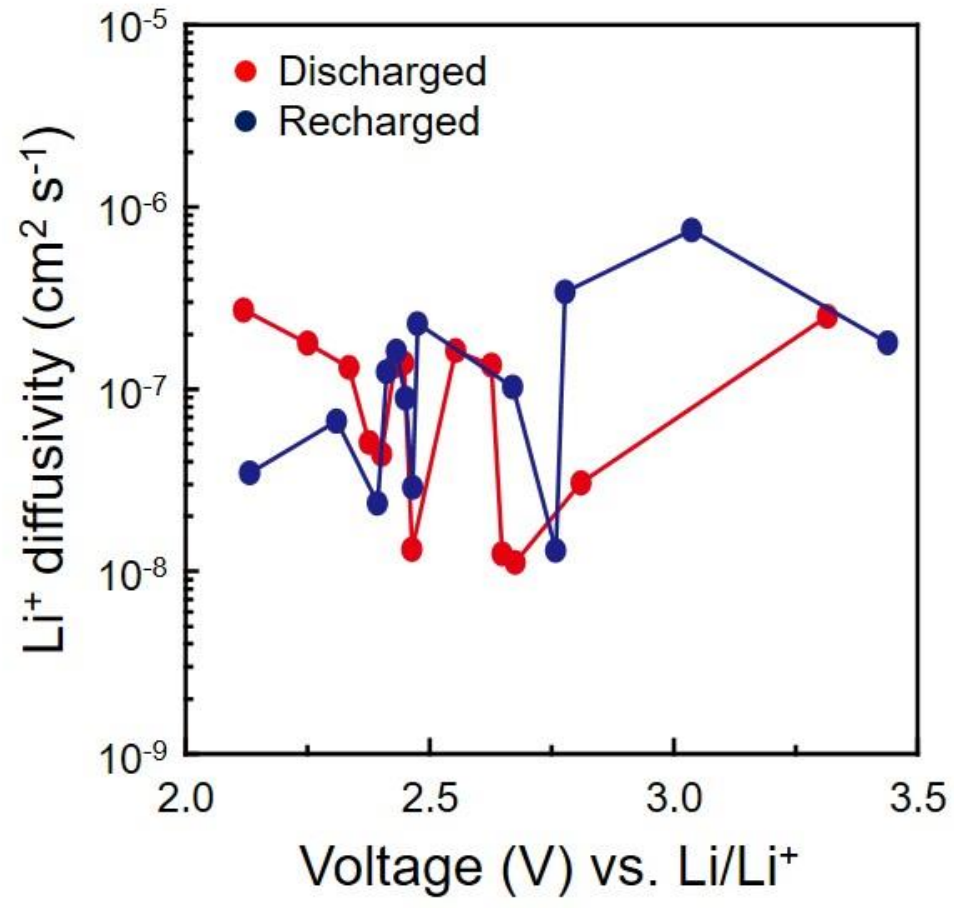

Figure S9. Diffusion coefficient of $\mathrm{Li}^{+}$ions calculated from GITT methods versus potential during discharging (red) and charging (blue). 


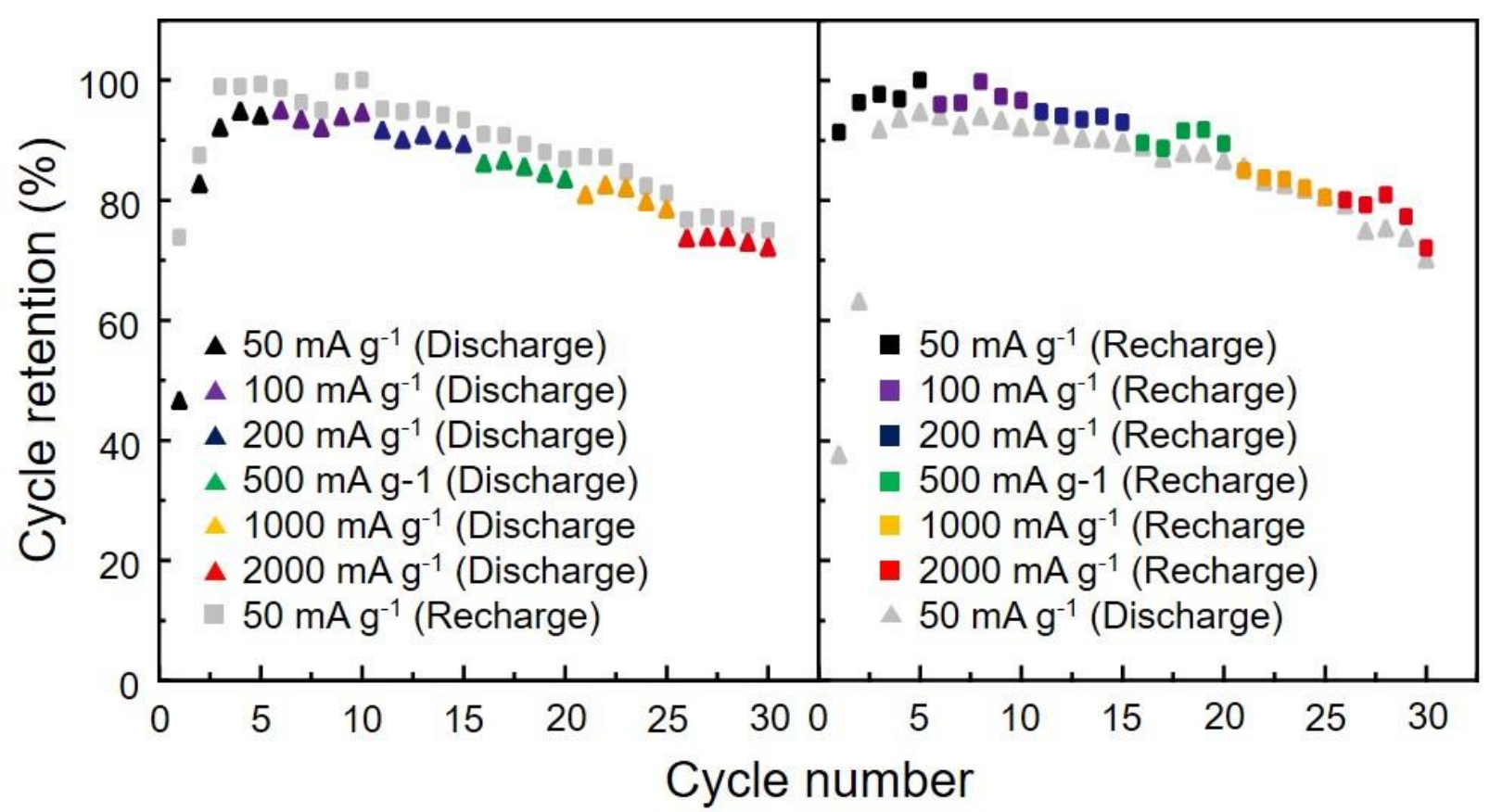

Figure S10. Results of rate capability tests performed with constant charge or constant discharge at $50 \mathrm{~mA}$ $\mathrm{g}^{-1}$, showing no specific limitation in lithiation or delithiation process.

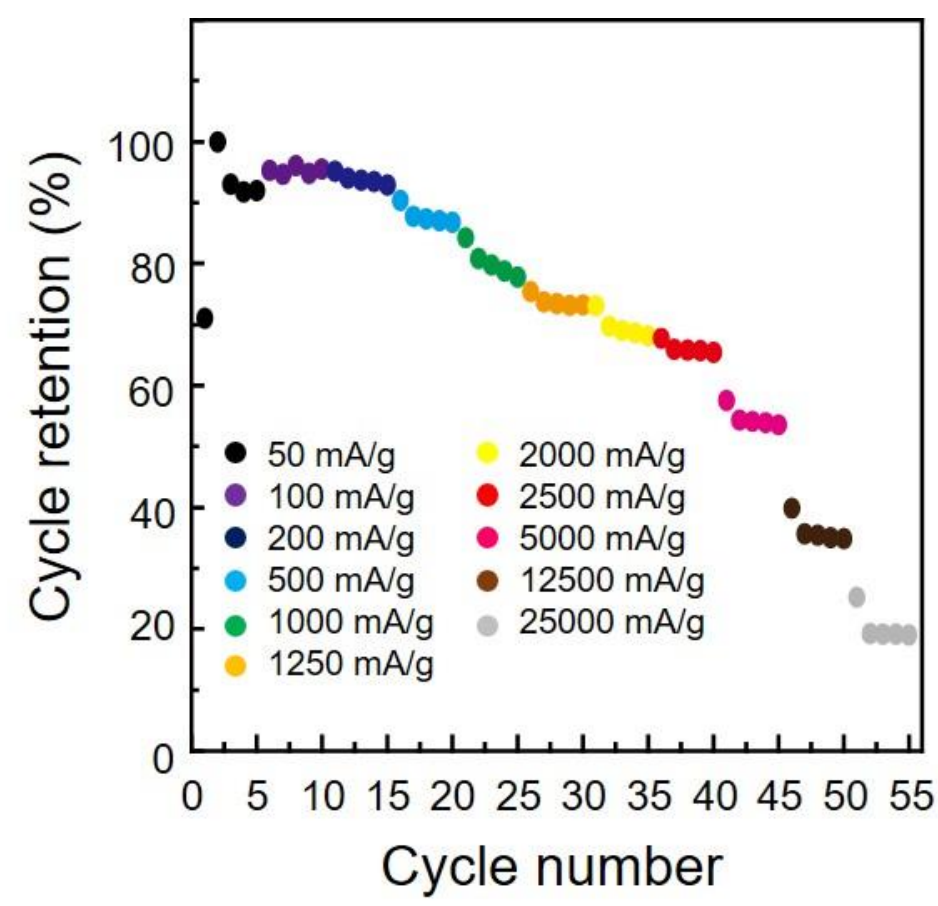

Figure S11. The rate capability of phenoxazin-3-one electrode at the ultrafast (dis)charging rates up to 25 $\mathrm{A} \mathrm{g}^{-1}$. 


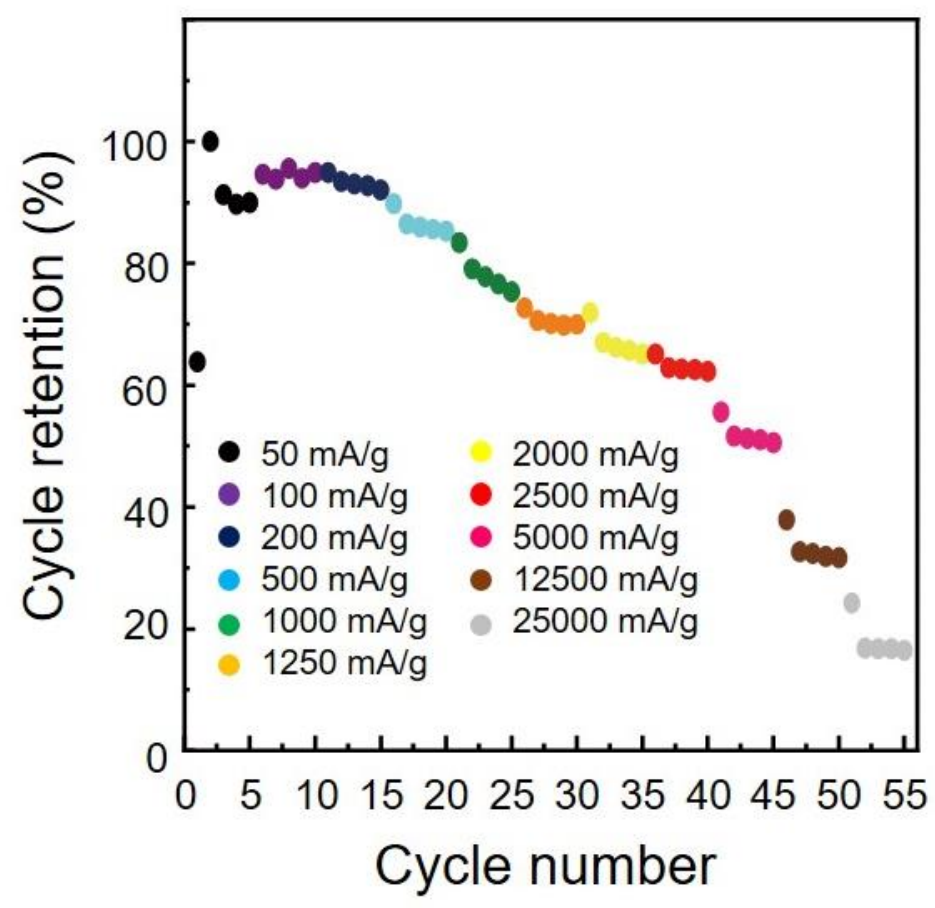

Figure S12. The pure rate capability of phenoxazin-3-one at the ultrafast (dis)charging rates up to $25 \mathrm{~A} \mathrm{~g}^{-}$ 1 .

\section{Note S4.}

Cyclic voltammetry at various scan rates was carried out in order to investigate charge-storage mechanism. Cyclic voltammograms at various scan rates are presented in Figure 3d. Anodic and cathodic peaks were assigned as A, B and C, D, respectively. We applied two methods to evaluate charge-storage mechanism. The first method is based on equation (2), where $i$ is the peak current, $v$ - the scan rate, $a$ - constant, and $b$ - value, determining battery (0.5) or capacitive (1.0) behavior. ${ }^{9,10}$ Equation (2) can be transformed to equation (3) after "logarithmation":

$$
\begin{gathered}
i=a v^{b} \\
\log (i)=\log (a)+b \log (v)
\end{gathered}
$$

According to this method, constant $a$ can be omitted and $b$ can be easily determined as a slope of the line in the $\log (i) v s . \log (v)$ plot. The $b$ values were estimated of $0.67,0.67,0.53$, and 0.77 for $\mathrm{A}, \mathrm{B}, \mathrm{C}$, and D peaks, respectively (Figure 3d, inset). The second method is based on linear correlation of peak currents $\left(I_{p}\right)$ and scan rates $(v)$ by a series plots of $I_{p}$ versus $v^{b}$ with various $b=0.5-1.0$ (Figure S13). ${ }^{11}$ The best linear fit with a zero intercept for each peak were determined separately. Thus, $b=0.7$ was obtained for peaks $\mathrm{A}$ and $\mathrm{D}$, while $b=0.5$ and 0.6 for the $\mathrm{C}$ and $\mathrm{B}$ peaks, respectively. 

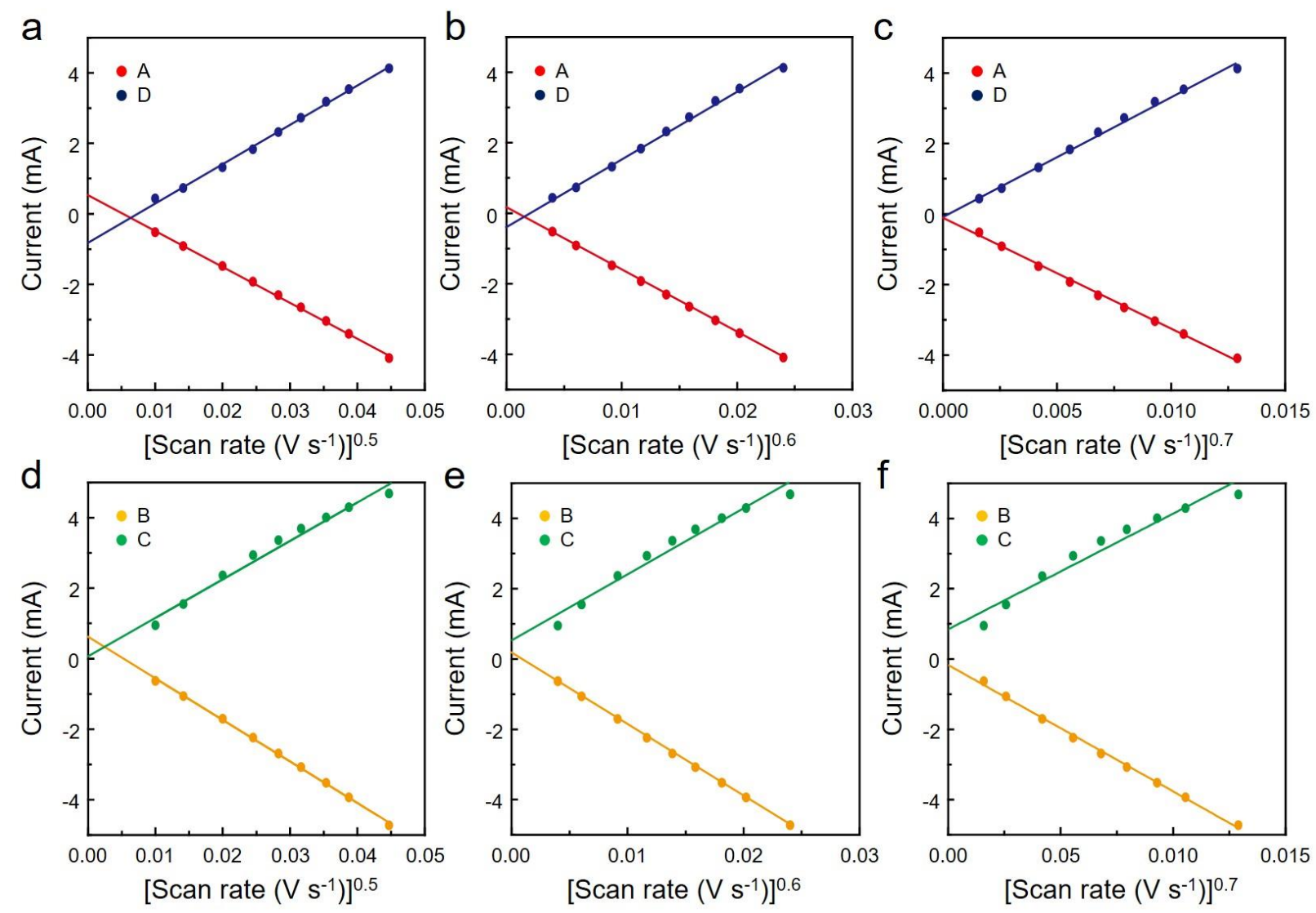

Figure S13. Investigation of charge storage mechanism: the correlation between the peak currents and scan rate $\left(v^{b}\right)$ with various $b$. (a), (b) and (c) Linear correlation of peaks current of the first redox reaction (peaks A and D) and scan rate and with $b=0.5,0.6,0.7$, respectively. (d), (e) and (f) Linear correlation of peaks current of the second redox reaction (peaks $\mathrm{B}$ and $\mathrm{C}$ ) and scan rate and with $b=0.5,0.6,0.7$, respectively. 

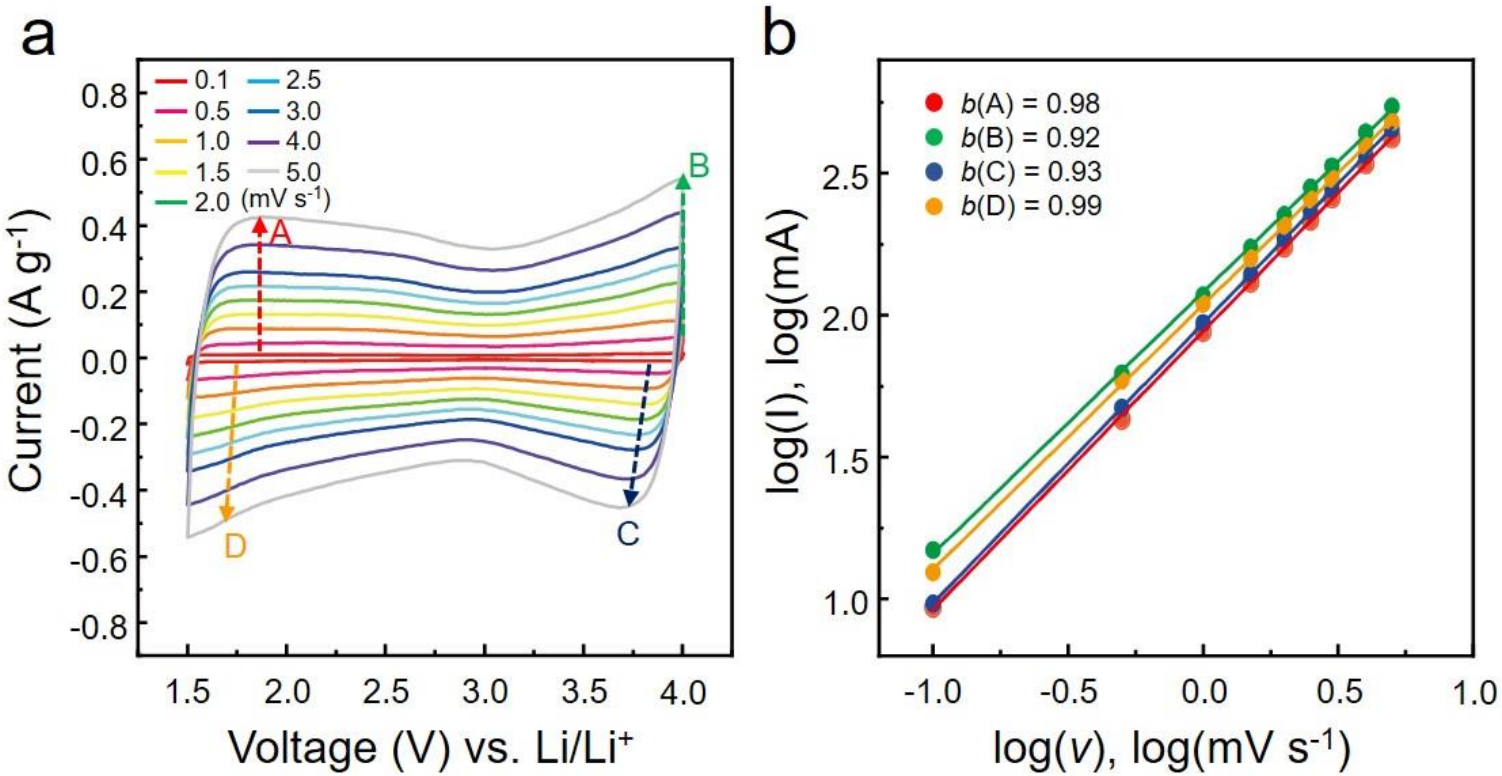

Figure S14. (a) CV curves obtained at various scan rates of the electrode without phenoxazin-3-one. (b) Linearity correlation between the logarithmic current, $\log (I)$, and sweep rate, $\log (v)$, of the electrode without phenoxazin-3-one. 
a<smiles>O=c1ccc2nc3ccc(O)cc3oc-2c1</smiles>

7-hydroxy-3H-phenoxazin-3-one (phenoxazin-3one/conjugated molecule)

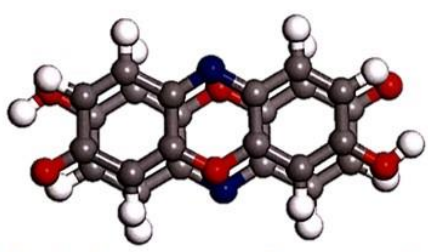

Stacked phenoxazin-3one molecules
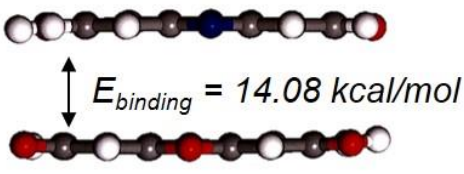

b

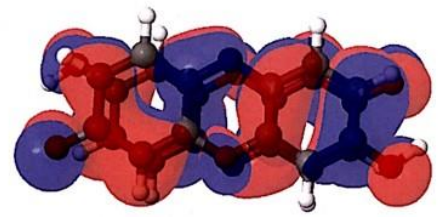

Top view

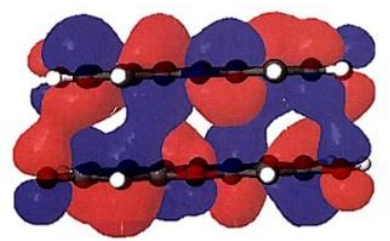

Side view

HOMO of stacked phenoxazin-3-one

molecules<smiles>O=C1CCC2NC3CCC(O)CC3OC2C1</smiles>

7-hydroxydecahydro-1H-phenoxazin-3(2H)-one (control group/nonconjugated molecule)

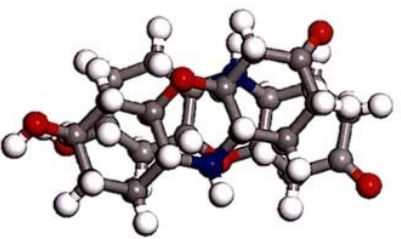

Stacked phenoxazin-3(2H)-one molecules
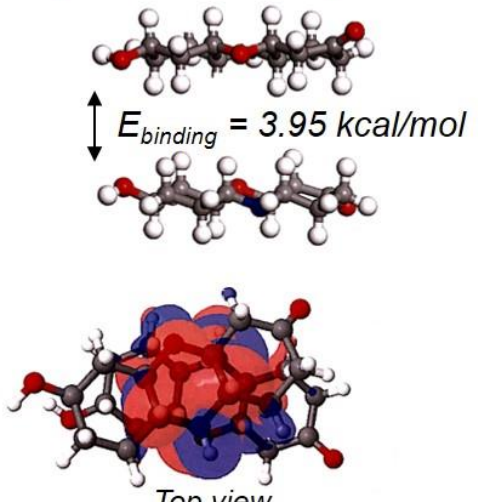

Top view

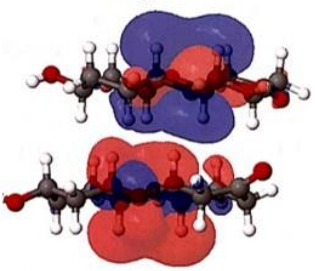

Side view

$\mathrm{HOMO}$ of stacked phenoxazin-3(2H)-one

molecules

Figure S15. $\pi-\pi$ interactions between two phenoxazin-3-one molecules. (a) Molecular structure of phenoxazin-3-one (conjugated) and phenoxazin-3(2H)-one (control group/nonconjugated) and binding energy of stacked two phenoxazin-3-one molecules and stacked two phenoxazin-3(2H)-one molecules. The binding energy of stacked two phenoxazin-3-one molecules $(14.08 \mathrm{kcal} / \mathrm{mol})$ showed higher energy than that of stacked two phenoxazin-3(2H)-one molecules $(3.95 \mathrm{kcal} / \mathrm{mol})$, which is attributed to the stabilization of phenoxazin-3-one by $\pi-\pi$ stacking (b) Highest occupied molecular orbital (HOMO) structure of stacked phenoxazin-3-one and stacked phnoexazin-3-(2H)-one molecules. The HOMO of the stacked phenoxazin3-one molecules consist as bonding orbital by hybridizing the conjugate orbital of two phenoxazin-3-one molecules. 


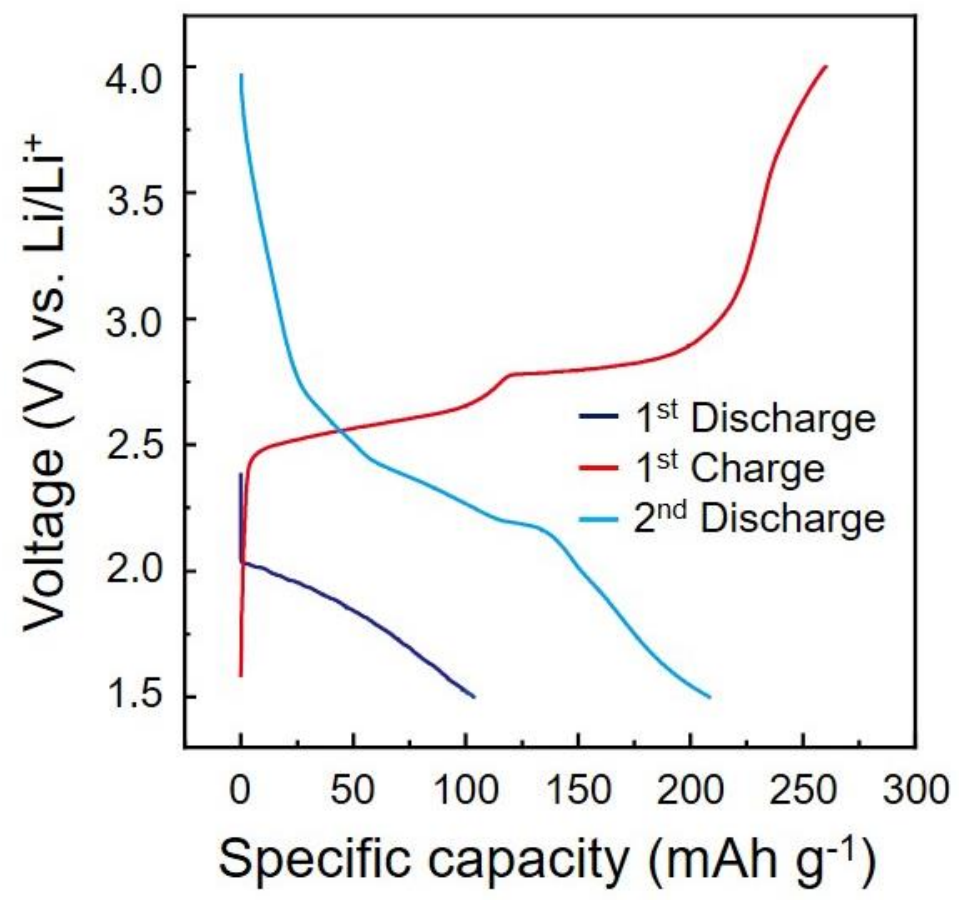

Figure S16. The electrochemical response of phenoxazin-3-one from the operando Raman cell. The operando Raman cell was cycled at $200 \mathrm{~mA} \mathrm{~g}^{-1}$ with discharge and charge cut-off voltages of $1.5 \mathrm{~V}$ and 4.0 $\mathrm{V}$, respectively.

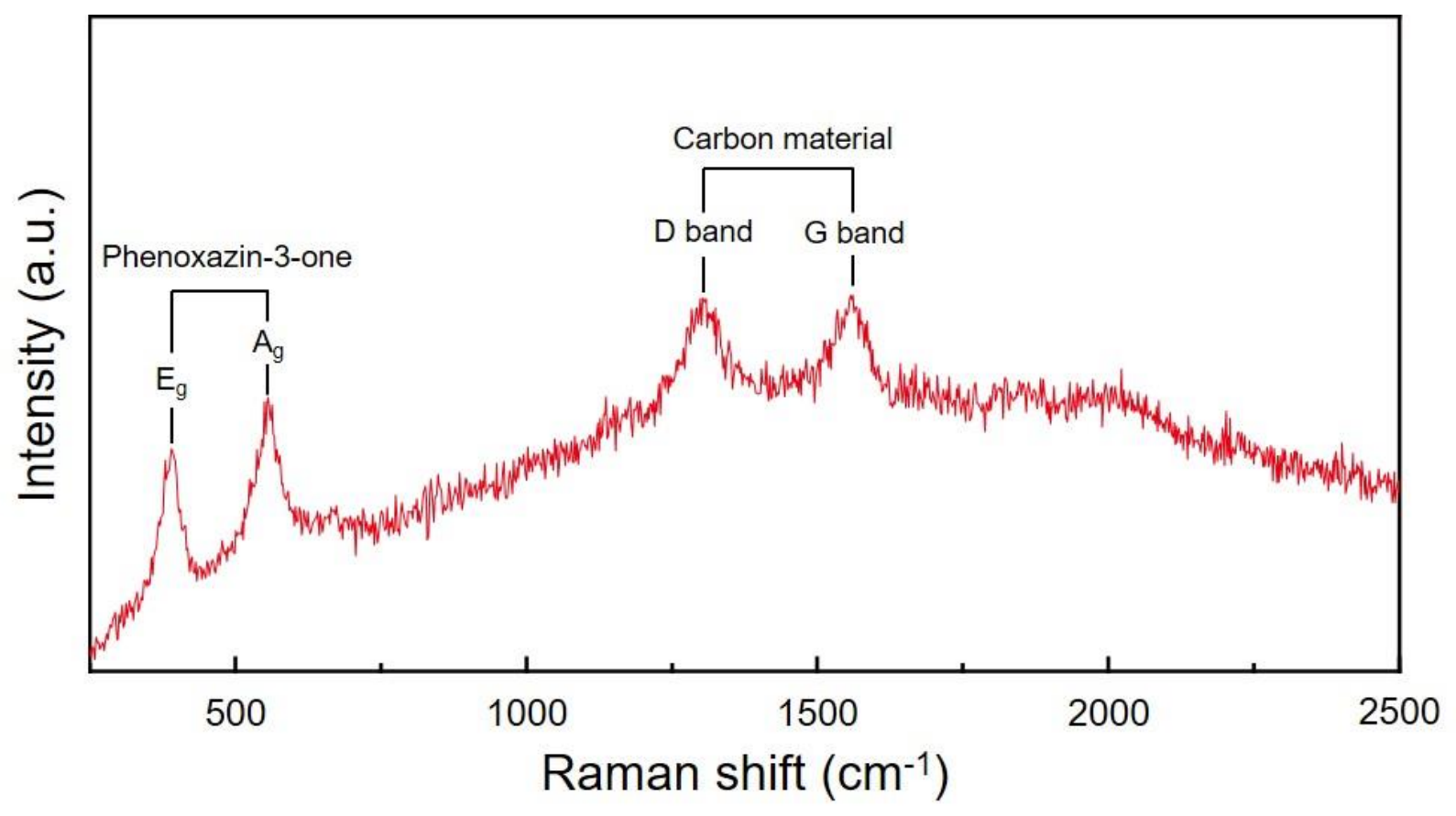

Figure S17. Full Raman spectrum at OCV to contain carbon region. 


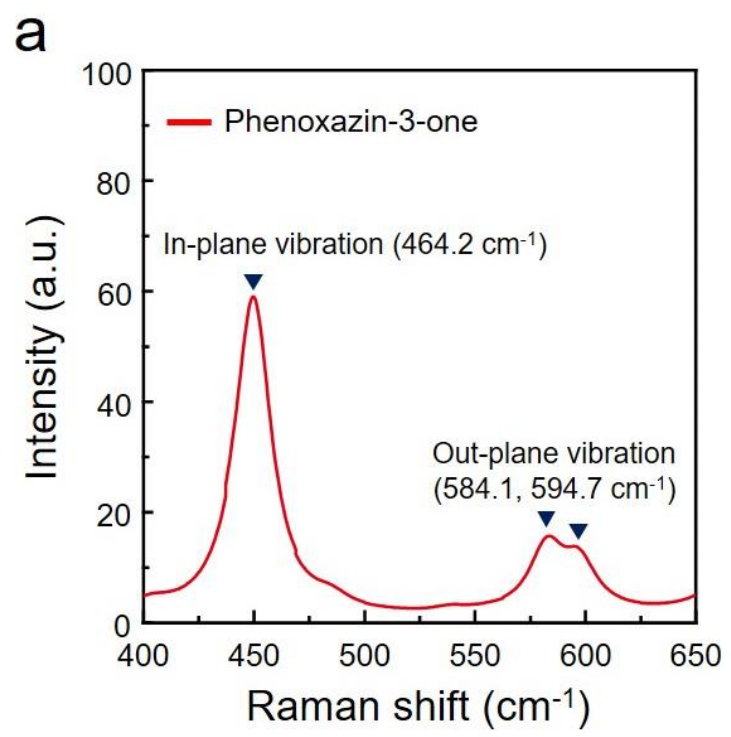

b

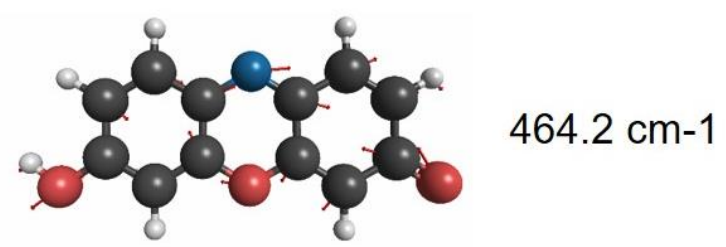

In-plane vibration

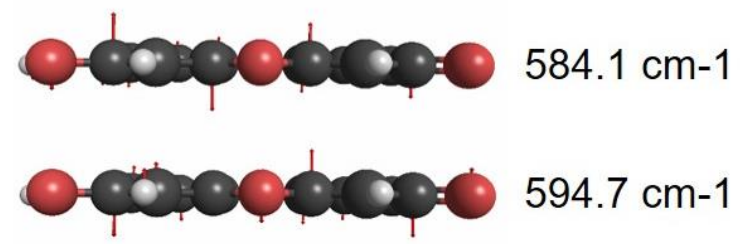

Out-plane vibrations

Figure S18. (a) Raman spectrum of phenoxazin-3-one calculated by DFT (B3LYP hybrid functional). (b) The DFT-predicted nuclear motion of phenoxazin-3-one with in-plane and out-plane vibrations. Arrows represent the mass-weighted displacements of the individual atoms.

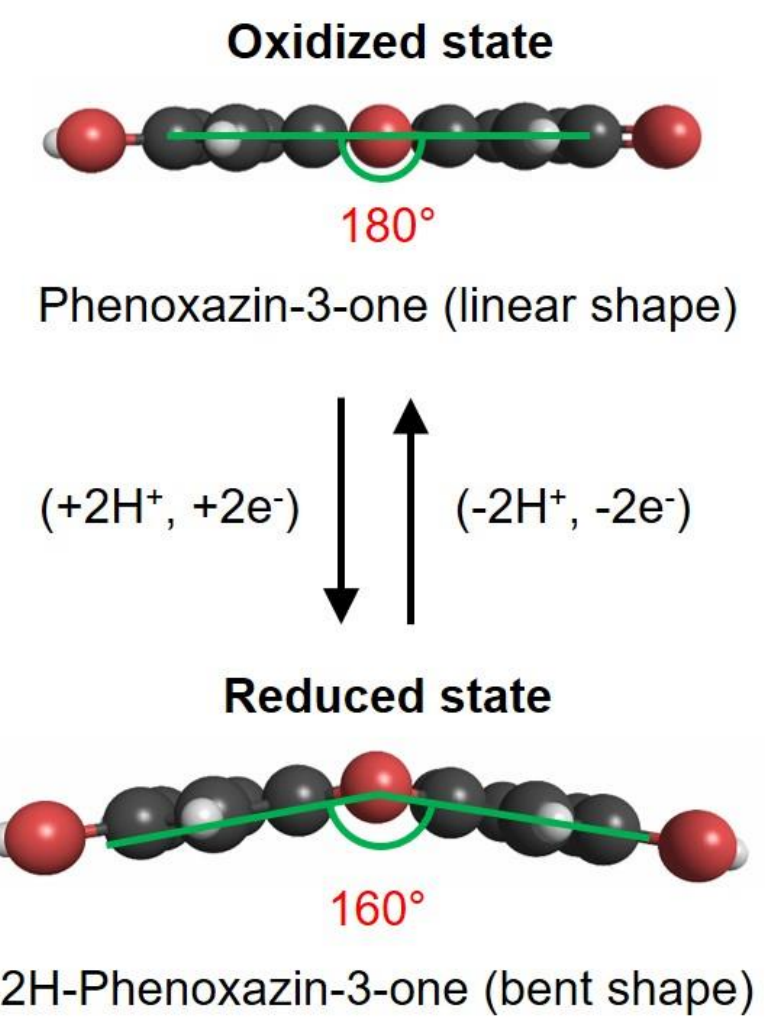

Figure S19. Side view of phenoxazin-3-one and 2H-phenoxazin-3-one. Conjugated ring of phenoxazin-3one had linear geometry, while $2 \mathrm{H}$-phenoxazin-3-one only showed the bent geometry. 


\section{Note S5.}

The Ragone plot of phenoxazin-3-one and other various single molecules is a good gauging tool to highlight the advantage of phenoxazin-3-one as depicted in Figure 6c. Phenoxazin-3-one cathode shows notably high energy densities of $597 \mathrm{Whkg}^{-1}$ at $0.8 \mathrm{C}$. Still high energy density of $176 \mathrm{Whkg}^{-1}$ could be delivered even at $50 \mathrm{C}$, which is corresponding to the high power density $\left(26,875 \mathrm{Wkg}^{-1}\right)$. We evaluated energy and power densities using the discharge capacity of only phenoxazin-3one at each C-rate because of relatively high capacity contribution of the carbon additive Values in Table S1, Figure 6 and Figure S20 were available in the literature. ${ }^{12-18}$ However several studies did not report energy and power densities, therefore we estimated them to the best of our abilities. Since the energy density is the area under discharge curve, we calculated energy densities as the product of the average discharge voltage and specific discharge capacity (see equation (2)). The molecules showing different plateaus with significant difference in voltage and/or discharge capacities are calculated by sum of each plateau contribution (i.e., sum of products of the plateau voltage and corresponding discharge capacity at the given plateau (see equation (3)).

$$
\begin{array}{cl}
\text { Energy density }=\mathrm{V} \times \mathrm{Q} & \text { equation (2) } \\
\text { Energy density }=\mathrm{V}_{1} \times \mathrm{Q}_{1}+\mathrm{V}_{2} \times \mathrm{Q}_{2} & \text { equation (3) }
\end{array}
$$

Important to note that the power densities in various sources were calculated via different methods, which oftentimes leads to the discrepancy between the values calculated for the same molecule. In our work, we estimated power densities for each molecule using both methods.

The more general method expresses the power density as the product of discharge current and average discharge voltage (see equation (4)). However this method represented decrease of power density at high current values only due to ohmic drop. According to the another method, the power density is expressed as the product of energy density at certain current and corresponding rate value, as shown in equation (5). This method reflects the effect of both ohmic drop and limitations in kinetics, which can be evidenced from decrease of accessed charge and average voltage at increased current densities, the product of which is the energy density. The Ragone plot in Figure 6c is presented based on the equation (4) since it is oftentimes used in the literature and represents the absolute power. However both methods are reported in the literature, therefore the Ragone plot based on the equation (5) is also depicted in Figure S20 as well.

$$
\begin{array}{cl}
\text { Power density }=\mathrm{I} \times \mathrm{V} & \text { equation (4) } \\
\text { Power density }=\text { Energy density } \times \text { C-rate } & \text { equation (5) }
\end{array}
$$

The discharge voltage in the Table $\mathrm{S} 1$ is the value reported in the literature, or the average for several redox reactions if not reported. Several p-type organic molecules operated at the higher voltage, however, they are not included due to their poor stability and capacity. ${ }^{19,20}$ 
Table S1. Summarized parameters used for comparison of phenoxazin-3-one to other single molecule electrodes.

\begin{tabular}{|c|c|c|c|c|c|c|c|c|}
\hline & $\begin{array}{c}\text { Discharge voltage } \\
\text { (V) }\end{array}$ & $\begin{array}{l}\text { Capacity (mAh } \\
\mathrm{g}^{-1} \text { ) }\end{array}$ & $\begin{array}{l}\text { Capacity } \\
\text { retention } \\
\left(\mathrm{mAh} \mathrm{g}^{-1}\right)\end{array}$ & $\begin{array}{c}\text { Capacity } \\
\text { retention (\%) }\end{array}$ & $\begin{array}{l}\text { Energy density } \\
\qquad\left(\mathrm{Wh} \mathrm{kg}^{-1}\right)\end{array}$ & $\begin{array}{c}\text { Rate capability } \\
\text { at } 2 \mathrm{C}(\%)\end{array}$ & $\begin{array}{l}\text { Rate capability } \\
\text { at } 5 \mathrm{C}(\%)\end{array}$ & $\begin{array}{c}\text { Rate capability } \\
\text { at } 10 \mathrm{C}(\%)\end{array}$ \\
\hline Phenoxazin-3-one* & 2.5 & 238 & 200 & 84 & 597 & 86 & 70 & 63 \\
\hline Phenoxazin-3-one & 2.5 & 297 & 260 & 87.5 & 745 & 87 & 78 & 65 \\
\hline TPB & 2.5 & 223 & 217 & 93 & 527 & 80.7 & 78.5 & 69.5 \\
\hline BFFD & 2.49 & 234 & 205 & 88 & 518 & 93 & 90 & 88 \\
\hline$(-)-N D I-\Delta$ & 2.37 & 145 & 114 & 78.4 & 307.6 & 90 & 88 & 83 \\
\hline DAP & 1.7 & 256 & 226 & 88.6 & 329.8 & 52.9 & 48.8 & 35.3 \\
\hline$A Q$ & 2.28 & 220 & 150 & 68.2 & 465 & 54.5 & 27.3 & 22.7 \\
\hline DANQ & 2.2 & 255 & 248 & 97 & 550 & 78.4 & 62.4 & 55.7 \\
\hline$N Q$ & 2.25 & 177 & 150 & 84.7 & 389 & 84.7 & 65 & 42.4 \\
\hline AQDS & 2.41 & 130 & 129 & 91 & 313 & 55.7 & 23.1 & 6 \\
\hline PTO/Carbon & 2.59 & 360 & 80 & 22.2 & 932 & $70.3^{\mathrm{a})}$ & N/A & $\mathrm{N} / \mathrm{A}$ \\
\hline PTO IL/AL ${ }_{2} \mathrm{O}_{3}$ & 2.4 & 350 & 253 & 72.3 & 843 & N/A & N/A & N/A \\
\hline
\end{tabular}

* The values in brackets show pure phenoxazin-3-one performance excluding carbon additive contribution to the capacity.

a) The rate capability at $1 \mathrm{C}$ was used due to absence of the data at higher $\mathrm{C}$ rates. 


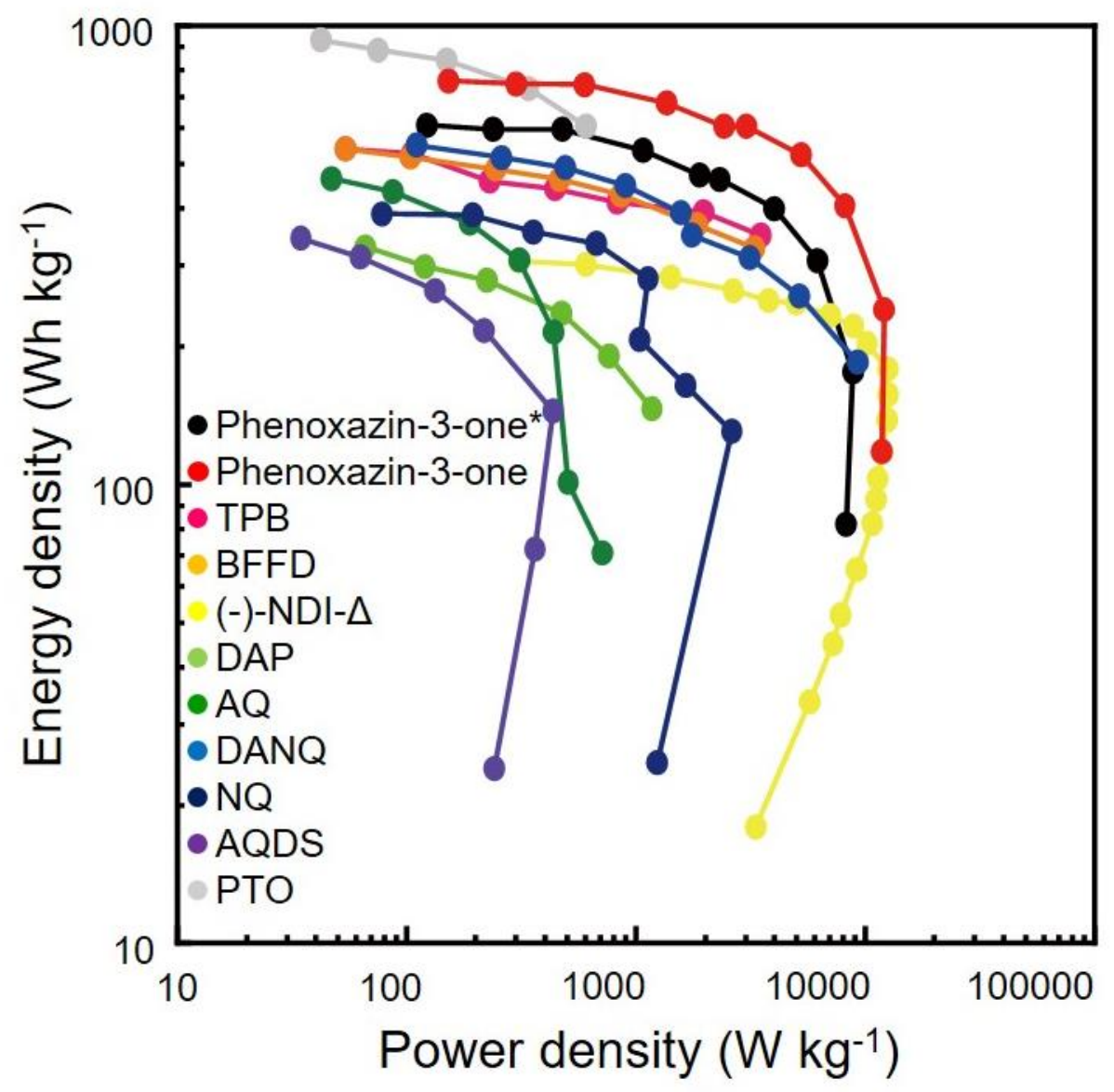

Figure S20. Ragone plots of phenoxazin-3-one along with various single molecules, where power densities estimated according to equation (5). The asterisk symbol $(*)$ represents pure phenoxazin-3-one performance excluding carbon additive contribution. 


\section{References}

(1) M. W. Schmidt, K. K. Baldridge, J. A. Boatz, S. T. Elbert, M. S. Gordon, J. H. Jensen, S. Koseki, N. Matsunaga, K. A. Nguyen, S. Su, T. L. Windus, M. Dupuis, J. A. Montgomery Jr, General atomic and molecular electronic structure system. J. Comput. Chem. 1993, 14, 1347-1363.

(2) A. D. Becke, Density-functional thermochemistry. III. The role of exact exchange. J. Chem. Phys. 1993, 98, 5648-5652.

(3) P. J. Stephens, F. J. Devlin, C. F. Chabalowski, M. J. Frisch, Ab initio calculation of vibrational absorption and circular dichroism spectra using density functional force fields. J. Phys. Chem. 1994, 98, 11623-11627.

(4) J. Tomasi, B. Mennucci, R. Cammi, Quantum mechanical continuum solvation models. Chem. Rev. 2005, 105, 2999-3094.

(5) T. Lu, F. Chen, Multiwfn: A multifunctional wavefunction analyzer. J. Comput. Chem. 2012, 33, 580592.

(6) T. Lu, F. Chen, Atomic dipole moment corrected Hirshfeld population method J. Theor. Comput. Chem. 2012, 11, 163-183.

(7) M. Tang, Y. Wu, Y. Chen, C. Jiang, S. Zhu, S. Zhuo, C. Wang, An organic cathode with high capacities for fast-charge potassium-ion batteries. J. Mater. Chem. A 2019, 7, 486-492.

(8) Z. Shen, L. Cao, C. D. Rahn, C.-Y. Wang, Least squares galvanostatic Intermittent titration technique (LS-GITT) for accurate solid phase diffusivity measurement. J. Electrochem. Soc. 2013, 160, A1842A1846.

(9) Y. Wang, Y. Song, Y. Xia, Electrochemical capacitors: mechanism, materials, systems, characterization and applications. Chem. Soc. Rev. 2016, 45, 5925-5950.

(10) H. Lindström, S. Södergren, A. Solbrand, H. Rensmo, J. Hjelm, A. Hagfeldt, S.-E. Lindquist, Li ${ }^{+}$ion insertion in $\mathrm{TiO}_{2}$ (anatase). 2. Voltammetry on nanoporous films. J. Phys. Chem. B 1997, 101, 77177722.

(11) N. Zhu, S. Han, S. Gan, J. Ulstrup, Q. Chi, Graphene paper doped with chemically compatible prussian blue nanoparticles as nanohybrid electrocatalyst. Adv. Funct. Mater. 2013, 23, 5297-5306.

(12) Z. Luo, L. Liu, Q. Zhao, F. Li, J. Chen, An insoluble benzoquinone-based organic cathode for use in rechargeable lithium-ion batteries. Angew. Chem. Int. Ed. 2017, 56, 12561-12565.

(13) Y. Liang, P. Zhang, S. Yang, Z. Tao, J. Chen, Fused heteroaromatic organic compounds for highpower electrodes of rechargeable lithium batteries. Adv. Energy Mater. 2013, 3, 600-605.

(14) D. Chen, A.-J. Avestro, Z. Chen, J. Sun, S. Wang, M. Xiao, Z. Erno, M. M. Algaradah, M. S. Nassar, K. Amine, Y. Meng, J. F. Stoddart, A rigid naphthalenediimide triangle for organic rechargeable lithium-ion batteries. Adv. Mater. 2015, 27, 2907-2912.

(15) B. Tian, Z. Ding, G.-H. Ning, W. Tang, C. Peng, B. Liu, J. Su, C. Su, K. P. Loh, Amino group enhanced phenazine derivatives as electrode materials for lithium storage. Chem. Commun. 2017, 53, 2914-2917.

(16) J. Lee, H. Kim, M. J. Park, Long-life, high-rate lithium-organic batteries based on naphthoquinone derivatives. Chem. Mater. 2016, 28, 2408-2416. 
(17) W. Wan, H. Lee, X. Yu, C. Wang, K.-W. Nam, X.-Q. Yang, H. Zhou, Tuning the electrochemical performances of anthraquinone organic cathode materials for Li-ion batteries through the sulfonic sodium functional group. RSC Adv. 2014, 4, 19878-19882.

(18) Y. Liang, P. Zhang, J. Chen, Function-oriented design of conjugated carbonyl compound electrodes for high energy lithium batteries. Chem. Sci. 2013, 4, 1330-1337.

(19) T. B. Schon, B. T. McAllister, P.-F. Li, D. S. Seferos, The rise of organic electrode materials for energy storage. Chem. Soc. Rev. 2016, 45, 6345-6404.

(20) M. E. Speer, M. Kolek, J. J. Jassoy, J. Heine, M. Winter, P. M. Bieker, B. Esser, Thianthrenefunctionalized polynorbornenes as high-voltage materials for organic cathode-based dual-ion batteries. Chem. Commun. 2015, 51, 15261-15264. 